\title{
Book Review: Revolutionary Keywords for A New Left by lan Parker
}

\author{
Eyal Clyne
}

Independent researcher, Manchester, UK, eyal.clyne@manchester.ac.uk, https://manchester.academia.edu/EyalClyne, ISNI 459940136 ORCID 219759522

Parker is an experienced Marxist activist, psychoanalyst and an established professor of critical psychology. His book is structured around 50 'keywords' which he recognises as prevalent in the circles of the broad struggle against injustice(s), beyond class. (Therefore, global poverty, homelessness or redistribution are excluded, or taken for granted, unlike the keywords neoliberalism and wages). As we would expect from a psychoanalyst, Parker identifies the chosen keywords through observing praxis, where he also seeks their meaning. The keywords were selected and are proposed by the analyst as significant, having surfaced in his years of activism in British radical-left groups. The sharp and concise analyses of each keyword senses the practiced meaning and their overarching direction within the 'New Left' (which is, as the book neglects to clarify, not new at all, but a term used to denote the post-1960s turn from materialist left to various cultural (and material) injustices; or in sociological terms, from Marx to Webber, Bourdieu and social-constructionism). As this work is not a suggestion to renew the Left with certain keywords, a more apt title for the book would be 'Revolutionary Keywords of/within the New Left.'

The majority of the book is dedicated to discussing each 'keyword' as a portal for unlocking complex Left-struggle issues in short and accessible essays. Reaching out to comrades, Parker exemplifies the potentials and pitfalls of every keyword, by analysing a wealth of experiences of radical moments and movements (and a few films and shows) from around the world (e.g. the Kurds, Chile, Greece, the USA, the UK, Palestine, India, Malta, Spain, Mexico, etc.), incorporating transdisciplinary lessons from feminism/gender, (non-psychologised) psychoanalysis, Queer, disability, black and postcolonial studies, and even from postmodernism and spiritualism, two big nonos in many Marxist circles. The exploration of experiences is so rich and global that it is sometimes difficult to follow the names of groups and acronyms, some of which are presupposed as the reader's existing knowledge. A glossary would indeed have been useful. Incidentally, the first keyword is academicisation, of which the book itself is an example, given the prior knowledge and level of register literacy required to decipher and access it (e.g. valorisation, vicarious, etc.).

Notwithstanding, these 'keyword' essays visit and offer a compass for coping with dilemmas that any critical 'broad struggle' activist would face sooner or later, such as rejecting anti-trans feminists, maintaining anti-Zionism without racism, and antiracism without being colourless (yet neglecting to mention poor and left-behind whites), as well as supporting the struggles of non-cisgender-heterosexuals while also avoiding pinkwashing nationality and liberalism (and where further thought about the subjectivity assumption embedded in self-definition of such identities is still required). ${ }^{1}$

\footnotetext{
${ }^{1}$ See: http://wp.me/p6LuKV-c7
} 
The keyword essays also touch on potential radical paradoxes and oxymora like recognising revolutionary reforms, structureless structures, and the conflicting need for unity while remaining disloyal to spectacles, leaders and parties. In this context, Parker makes a daring suggestion, almost in passing, for the rejection of subjectivity without removal of agency, offering an original solution for the agent-structure problem. ${ }^{2} \mathrm{Ac}$ cording to Parker's desubjectified agency, individual agency is a misleading ideological capitalist illusion, but collective action has true agency. Therefore, ultimately, despite the advocated disloyalty and even suspicion to structures, political parties, categories and camps, Parker adamantly campaigns for radical activism throughout, and rejects nihilist avoidance. However, how disloyalty to reified units and camps (and ideas?) can be possible without accepting individuality and subjectivity is something that still requires development.

Other keywords include: accelerationism, antagonism, appropriation, discourse, ecosocialism, empire, feminisation, globalisation, Islamophobia, multitude, occupy, performativity, prefigurative, psychoanalysis, recuperation, refusal, standpoint, transition, and young-girl. Of course, one can think of many more (I suggest: affect, barelife, biopolitics, citizenship, community, consent, cyborg, environmental refugees, ideology, Internet, keyboard activism, law, language, MeToo, misogyny, pacifism, reification, scientification, spatiality, technology, urbanisation, world-system, and Xenophobia); and the readership of Triple- $C$ would surely notice the absence of problems of media, technology and digital life (e.g. algorithms, cyber protest, computer literacy, disconnection, digital globalisation, digital labour, digital alienation, digital participation, digital surveillance, and (anti-)social media commodification).

While most of the book is devoted to the said fragmented analytic activism manifesto, it concludes with a hypothesis that postulates a meta-discursive shift from the keywords Raymond Williams (1976) has recognised, ${ }^{3}$ whereby keywords from the first half-century since the formative Russian Revolution (1917-1967) were arguably organisable along a two-dimensional binary communist (and, I would add, modernist) axis, whereas Parker's subsequent fifty years' keywords (1967-2017) are multidirectional and multidimensional, perhaps in the spirit of liquid, late, or post- modernity. This fascinating periodised hypothesis could, however, be in tension with the book's mitigation of the keywords as merely debateable suggestions and dynamic examples, rather than a fixed corpus or a reified lexicon. In fact, reification is nearly inevitably determined by the choice of medium (i.e. book). Further attention is also required to the very metaphor of the Left, as enforcing an image of spectrum, binary or dialectic, perhaps even symmetry, between two political agendas. And, given the diffused, boundaryless and fluid nature of the radical Left, the binding notions of "Left" and radicality will also need to be treated.

Still, in conclusion, the book both provides a wealth of very useful corpus of knowledge on left, activism and resistance, and opens up the space for further articulation of discourse and ideas worth fighting for.

\section{References}

Williams, Raymond. 1976. Keywords: A Vocabulary of Culture and Society. London: Fontana.

${ }^{2}$ Cf. https://wp.me/p6LuKV-7

${ }^{3}$ See the ongoing project at http://keywords.pitt.edu/. 


\section{About the Author}

\section{Eyal Clyne}

Eyal Clyne is a transdisciplinary culture researcher, qualitative discourse/ideology analyst, and sociologist with a background in anthropology, sociology of knowledge, Saidian theory, media, communications, Israel-Palestine, Israeli society, and Middle East and Islam. Clyne holds a $\mathrm{PhD}$ from the University of Manchester and his book on Israeli discourse and Middle Eastern studies is forthcoming (Routledge). 